\title{
Geestelijke verzorging in een levensbeschouwelijk divers en geseculariseerd land ${ }^{\mathrm{I}}$
}

\author{
Joantine Berghuijs*
}

\begin{abstract}
Summary
Measured in terms of church membership and church attendance, The Netherlands are rapidly secularizing. However, the country has a very diverse population in terms of religious/spiritual orientations, including the phenomenon of 'multiple religious belonging' that cuts through all traditional divisions. All in all, there is a majority of over $60 \%$ that is involved in some form of religion or spirituality. In most cases, interfaith spiritual care is unproblematic for both spiritual caregivers and for their clients, except in case of religion-specific rituals. Recent developments enhance the presence and visibility of spiritual caregivers and their broad employability. Concerns about profiling of the profession, and fragmentation of types of accreditation are discussed.
\end{abstract}

\section{Het veelkleurige religieuze landschap in Nederland}

Als het gaat om religie in Nederland zijn niet alleen de primaire kleuren van de bekende wereldreligies te zien, maar is er ook een flinke groep religieuze creatievelingen, mensen die elementen uit verschillende religieuze tradities combineren in hun leven. In mijn onderzoeksproject aan de Vrije Universiteit hebben we dit 'meervoudige religieuze betrokkenheid' (MRB) ofwel multiple religious belonging genoemd.

Het christendom is nog steeds de numeriek belangrijkste religie in ons land, maar de percentages zijn snel gedaald. In 2018 bracht het SCP een rapport uit met de titel Christenen in Nederland (De Hart \& Van Houwelingen 2018). Figuur 1 is ontleend aan dat rapport. Daaruit blijkt dat zowel het percentage dat een religieuze opvoeding heeft gehad, het percentage dat kerklid is en het percentage dat minstens één keer per maand naar de kerk gaat een duidelijk neerwaartse trend vertoont, die zich vooralsnog niet lijkt te stabiliseren.

\footnotetext{
* Joantine Berghuijs was tot 2018 onderzoeker op het gebied van nieuwe vormen van spiritualiteit en religie aan de Vrije Universiteit Amsterdam. Momenteel heeft zij een functie als geestelijk verzorger in verpleeghuis Rumah Kita in Wageningen.
} 
Figuur 1. Betrokkenheid bij geloof en kerk in Nederland, 1983-2016 (Bron: SCP)

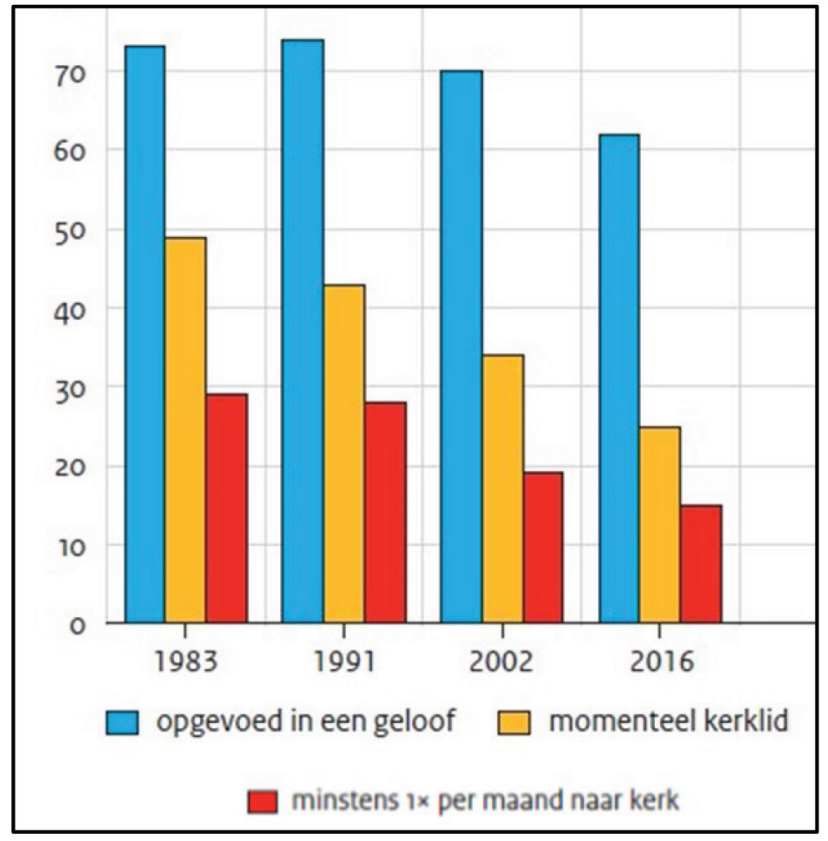

Maar zijn religieuze opvoeding, kerklidmaatschap en kerkbezoek tegenwoordig wel de beste en enige relevante indicatoren van religieuze betrokkenheid of activiteit? Een bredere en meer genuanceerde benadering werd gehanteerd in God in Nederland (Bernts \& Berghuijs 2016), waar naast 25\% kerkleden en $7 \%$ leden van een andere religieuze traditie, ook $27 \%$ mensen aangaven 'ongebonden spiritueel' en/of 'ongebonden religieus' te zijn. Opgeteld resulteert dit in bijna 60\% van de bevolking die met religie of spiritualiteit bezig is. Duidelijk wordt dan ook dat religie en spiritualiteit niet beperkt worden door kerkmuren, want binnen die muren zijn ongeveer evenveel mensen die religieus of spiritueel zijn als erbuiten. Kerkelijke betrokkenheid is duidelijk niet de enige indicator van religieuze of spirituele betrokkenheid.

In het project multiple religious belonging heb ik een aantal zogenoemde modaliteiten van religieuze betrokkenheid gebruikt, zijnde de verschillende manie- 
ren waarop mensen een connectie kunnen hebben met een religieuze traditie. Deze modaliteiten zijn:

- Affiniteit (inspiratie, verbondenheid, aantrekkingskracht);

- Praktijken (rituelen, materiële aspecten), bijvoorbeeld: bidden, mediteren, vasten en bezit van voorwerpen met een religieuze betekenis voor de betrokkene);

- Ideologie (overtuigingen);

- Ervaringen en emoties gerelateerd aan religie;

- Ethiek (waarden), ontleend aan religie;

- Sociale participatie (deelname aan religieuze groeperingen, lidmaatschap, functie);

- Zelfidentificatie (ik beschouw mezelf als een christen, moslim, ...).

We hebben deze modaliteiten in kaart gebracht met behulp van een enquête onder een representatieve steekproef van de bevolking, met meerdere vragen voor elke modaliteit.

Voor elke modaliteit waarop een respondent 'scoorde', kon deze in een vervolgvraag aangeven met welke religie of religies zijn of haar betrokkenheid verband houdt. Als iemand een connectie aangaf met meer dan één religie op een modaliteit of over verschillende modaliteiten verdeeld, telden we hem of haar als meervoudig religieus betrokken. Het resultaat was dat $41 \%$ aangaf betrokken te zijn bij slechts één religie ('monoreligieus'), en $23 \%$ bij meer dan één religie (meervoudig religieus). Opgeteld resulteert dit in $64 \%$ die op een of andere manier betrokken is bij religie of spiritualiteit (Berghuijs 2018, hoofdstuk 2 en 3 ).

MRB is dus geen marginaal fenomeen. Voor alle duidelijkheid: het is niet zo dat het vooral buiten de kerken speelt, integendeel: van degenen die lid zijn van de katholieke of protestantse kerk is $40 \%$ MRB'er. De belangrijkste combinatie van religies onder de ondervraagden is die van christendom en boeddhisme (13\%). Deze combinatie hangt samen met de toenemende belangstelling voor oosterse religies in het westen. Campbell betoogt dat de oosterse wereld in economische zin verwestert, maar dat het in spirituele zin andersom is. Als een van de belangrijke redenen hiervoor noemt hij de ontwikkeling van de natuurwetenschap, die heeft geleid tot een verlies van plausibiliteit als het gaat om de bovennatuurlijke waarheidsclaims van het christendom. In oosterse tradities ligt er minder nadruk op doctrines, en meer op praktijken, ervaringen en intuitie, kenmerken die passen bij het individualisme van deze tijd (Campbell 2007). 
Figuur 2. Overlap tussen MRB en andere groepen in percentages van de bevolking
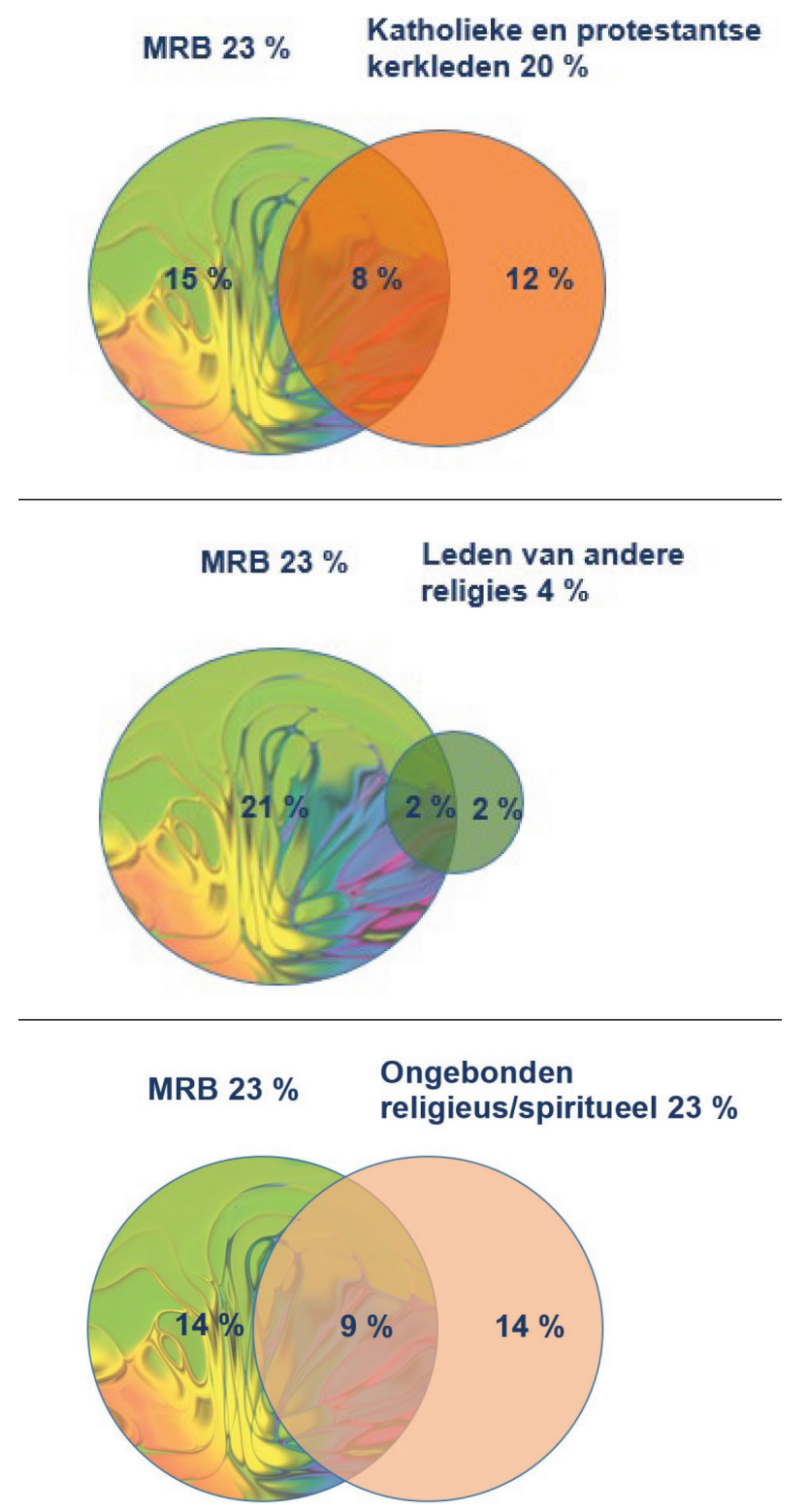

MRB gaat dwars door allerlei andere indelingen heen (zie figuur 2), zoals die naar al dan niet kerklid of lid van een andere religieuze gemeenschap zijn, of naar al dan niet ongebonden spiritueel of religieus zijn. En in alle drie de gevallen is de MRB-groep groter dan of gelijk aan de overlappende andere groep. 
Omdat MRB'ers een belangrijke en nog niet zo heel bekende groep vormen, geef ik nog enkele resultaten van het vervolgonderzoek (Berghuijs 2018, hoofdstuk 4). MRB'ers, vergeleken met een groep monoreligieuzen, die voornamelijk uit christenen bestond:

- zijn flexibeler als het gaat om religieuze opvattingen en gemeenschappen, in die zin dat ze die gemakkelijker achter zich laten als ze zich er niet meer bij thuis voelen;

- hebben vaker een pluralistische kijk: ze zijn ervan overtuigd dat meer dan één (of zelfs alle) religies tot hetzelfde doel leiden;

- leggen de nadruk op overeenkomsten tussen religies in plaats van zich zorgen te maken over verschillen, en richten zich bijvoorbeeld op universele mystieke aspecten of op liefde;

- zoeken wijsheid in plaats van waarheidsclaims;

- leggen meer nadruk op praktijken en ervaringen dan op doctrines;

- zien religie vaker als een zoektocht: ze beschouwen nieuwe inzichten als tijdelijk, en zijn niet bang voor twijfels.

Deze bevindingen, aangevuld met wat een aantal geïnterviewden zei, lijken erop te wijzen dat MRB'ers religies vaak zien als intermediairs of instrumenten die ze kunnen gebruiken om een goed leven te leiden, bijvoorbeeld een gelukkig, liefdevol of compassievol leven. Sommigen gebruikten prachtige metaforen om uit te drukken hoe zij het naast elkaar bestaan van meerdere religies zien: zij beschreven ze bijvoorbeeld als wegwijzers, terwijl het leven zelf de weg is, of als de verschillende kanten van een diamant, als verschillende kledingstukken die je kunt aantrekken, als instrumenten in een orkest, die samen een symfonie kunnen voortbrengen, of als glas-in-loodramen die, hoe verschillend ze ook zijn, hetzelfde licht doorlaten.

\section{Gevolgen voor de geestelijke verzorging}

De beschreven grote religieuze diversiteit in ons land betekent voor geestelijk verzorgers dat zij zich zullen moeten bekwamen om van dienst te kunnen zijn aan mensen met een andere levensbeschouwelijke achtergrond, waaronder MRB'ers. Hoe gaan geestelijk verzorgers om met religieuze diversiteit en met MRB? Om hierachter te komen heb ik samen met Anke Liefbroer een enquête gehouden onder Nederlandse geestelijk verzorgers. De resultaten zijn in een aantal publicaties neergelegd (Berghuijs \& Liefbroer 2017, 2017a en b; Liefbroer \& Berghuijs 2017; Liefbroer \& Berghuijs 2019), waaruit ik hieronder 
enkele resultaten heb geselecteerd, die ik aanvul met recente ontwikkelingen. Zie voor de onderzoeksopzet de genoemde artikelen.

Wat betreft hun eigen religieuze flexibiliteit bevestigde $72 \%$ de stelling: 'Religie/levensbeschouwing is naar mijn idee vooral een persoonlijke zoektocht, waarbij je elementen uit verschillende religieuze tradities kunt combineren in je leven.' Een wat kleinere meerderheid (63\%) bevestigde dat ze zelf elementen van verschillende religieuze tradities in hun leven combineren. Onder de sectoren van de beroepsvereniging VGVZ werd het grootste percentage MRB'ers gevonden bij degenen die geautoriseerd zijn door de RING-GV $(85 \%)^{2}$

Met betrekking tot hun werk vroegen we de respondenten onder andere aan wat voor soort geestelijk verzorger ze dachten dat gesprekspartners de voorkeur zouden geven. Gemiddeld dachten de meesten dat christenen en moslims de voorkeur zouden geven aan een geestelijk verzorger met dezelfde levensbeschouwelijke oriëntatie, terwijl humanisten, MRB'ers en mensen zonder specifieke levensbeschouwelijke oriëntatie geen voorkeur zouden hebben. Ze wisten niet of joden, boeddhisten en hindoes een voorkeur hebben. Aanvullend stelde Anke Liefbroer in een van haar projecten de vraag aan cliënten zelf (Liefbroer 2020, hoofdstuk 6). Haar resultaten geven een ander beeld. Zij ondervroeg een aantal ziekenhuispatiënten. Gemiddeld hadden die evenveel waardering voor de gesprekken met geestelijk verzorgers van andere levensbeschouwelijke tradities als voor de gesprekken met geestelijk verzorgers van hun eigen traditie. Dit gold zelfs in die gevallen waarin de patiënten hun eigen geloof als exclusief beschouwden. De antwoorden op een andere vraag in onze enquête onder geestelijk verzorgers kunnen enig licht werpen op deze bevindingen. Als we kijken naar de thema's die in gesprekken naar voren komen, blijkt dat in alle groepen het meest voorkomende thema 'relaties' is, en niet religie. Religieuze betekenisgeving wordt door geestelijk verzorgers als tweede belangrijkste gespreksthema ingeschat voor gesprekspartners met een specifieke levensbeschouwelijke oriëntatie of MRB'ers. Maar vrij vaak zien geestelijk verzorgers in alle groepen betekenisgeving zonder expliciete verwijzing naar religie ook als een belangrijk gespreksonderwerp. Veel geestelijk verzorgers gaven aan dat het gesprek van persoon tot persoon belangrijker is dan de levensbeschouwelijke oriëntatie, die vaak niet eens aan bod komt.

In de antwoorden op een open vraag over uitdagingen voor de geestelijke verzorging werd de noodzaak genoemd om je als geestelijk verzorger te richten op de behoeften van je gesprekspartner, vanuit diens eigen levensbeschouwelijke oriëntatie, of door het vertalen van en vormgeven aan teksten en 
rituelen uit de diverse tradities zodat deze bruikbaar zijn als een zingevende taal voor iedereen in een geseculariseerde wereld. Deze opmerkingen lijken overeen te komen met de visie die ik aantrof onder geïnterviewde MRB'ers, die de religies beschouwen als intermediairs of instrumenten voor het leiden van een goed leven.

Inzicht in de houding van geestelijk verzorgers ten opzichte van religieuze diversiteit werd vervolgens onderzocht door hen een twaalftal stellingen voor te leggen die draaien om de vraag of zij bereid zijn en zich bekwaam achten om interlevensbeschouwelijke geestelijke verzorging (IGV) te leveren. Uit de resultaten blijkt dat geestelijk verzorgers die zelf uit verschillende religieuze bronnen putten, een positievere kijk hebben op IGV dan zij die dit niet doen. Significante verschillen tussen de beide groepen waren er bijvoorbeeld bij de volgende twee stellingen (scores op een schaal van $1=$ zeer mee oneens tot $5=$ zeer mee eens): 'Rituelen wil ik alleen of hoofdzakelijk uitvoeren met mensen met eenzelfde religieuze/levensbeschouwelijke oriëntatie als ikzelf heb' (2,4 voor MRB-geestelijk verzorgers en 2,9 voor niet-MRB geestelijk verzorgers) en 'Ik kan mijn eigen religieuze/levensbeschouwelijke oriëntatie op de achtergrond plaatsen' (4,3 resp. 3,8).

Ten slotte vroegen we de respondenten rechtstreeks of zij bereid zijn om IGV te leveren en zich daartoe competent achten. En vrijwel alle geestelijk verzorgers beantwoordden beide vragen met ja (96 resp. 95\%). Vervolgens is een regressieanalyse uitgevoerd om te bepalen welke persoonlijke en organisatorische factoren gerelateerd zijn aan opvattingen en evaluaties van IGV (Liefbroer \& Berghuijs 2019). Een van de belangrijkste bevindingen was dat de organisatie ertoe doet:

- Geestelijk verzorgers in zorginstellingen hebben een positievere kijk op IGV dan zij die in gevangenissen werken;

- Geestelijke verzorgers die territoriaal werken (dat wil zeggen per afdeling van hun instelling) staan positiever tegenover IGV dan zij die categoraal werken (alleen voor hun geloofsgenoten)

Wat betreft de laatste uitkomst kan men zich echter afvragen wat er eerst komt: de kip of het ei. Ontwikkelen geestelijk verzorgers die territoriaal werken, en mensen zien met een diversiteit aan levensbeschouwelijke oriëntaties een positievere kijk op IGV, of zoeken geestelijk verzorgers die al een positieve kijk op IGV hebben naar banen waar ze territoriaal kunnen werken? 
In gesprekken met geestelijk verzorgers bleek dat zij vaak terughoudend of afwijzend staan tegenover het uitvoeren van religie-specifieke rituelen. In dat geval zouden ze een religieuze specialist willen inschakelen. Ook kwam naar voren dat de gesprekspartner er voldoende vertrouwen in moet hebben dat de geestelijk verzorger kennis heeft van zijn of haar specifieke religieuze/culturele traditie. Iemand noemde dit 'culturele competentie'.

Omdat er maar weinig boeddhistische, islamitische en hindoeïstische geestelijk verzorgers aan onze de enquête meededen, voerde Anke Liefbroer een extra enquête uit onder deze groepen (Liefbroer 2020, hoofdstuk 5). De belangrijkste resultaten zijn dat:

- boeddhistische spirituele zorgverleners gewend zijn aan IGV, en

- islamitische en hindoeïstische geestelijk verzorgers vooral gericht zijn op hun medegelovigen, maar wel mogelijkheden voor IGV zien.

Een gevoelig punt vormde de versnippering in denominaties/accreditaties. De opvattingen onder de respondenten verschilden van 'achterhaald' tot 'ik wil vasthouden aan mijn eigen denominatie'. Hieraan gerelateerd is het thema over de noodzaak om de professie te onderscheiden van andere, bijvoorbeeld die van de psychologie. Ik kom hier in de discussie op terug.

Concluderend suggereren de beschreven resultaten dat religieuze diversiteit, MRB en IGV voor de meerderheid van de geestelijk verzorgers geen problemen opleveren. Ook cliënten lijken IGV te accepteren. Vertrouwen, en de relatie van mens tot mens blijkt van meer belang te zijn dan de specifieke religieuze oriëntatie van beide gesprekspartners. In geval van religie-specifieke rituelen willen geestelijk verzorgers liever een 'specialist' van de betreffende religie inroepen.

\section{Recente ontwikkelingen}

Veel respondenten in de enquête benadrukten de noodzaak tot versterking van het imago van de professie onder andere collega's, zodat duidelijk wordt dat de inzetbaarheid van geestelijk verzorgers breder is dan het bestaande 'kerkgerelateerde' imago suggereert. Diverse recente ontwikkelingen sluiten aan op deze brede interlevensbeschouwelijke inzetbaarheid van geestelijk verzorgers, en maken die brede inzetbaarheid ook zichtbaarder dan in het verleden. 
In lijn met de beschreven ontkerkelijking en levensbeschouwelijke diversiteit in ons land groeit het aantal mensen dat zich door de RING-GV laat accrediteren (de $\mathrm{SING}^{2}$ is gegroeid van $18 \%$ binnen de VGVZ ten tijde van onze enquête naar 26\% tegenwoordig). Daarmee is de SING de derde grootste sectie geworden na de protestanten en katholieken). Als gevolg kan verwacht worden dat het aantal MRB'ers onder de geestelijk verzorgers toeneemt, wat waarschijnlijk leidt tot nog meer steun voor interlevensbeschouwelijke geestelijke verzorging.

Daarnaast hebben geestelijk verzorgers in de corona-tijd meer aandacht gekregen van het publiek, door hun grotere zichtbaarheid in de ondersteuning van patiënten, zorgverleners en familieleden van patiënten. Verwacht mag worden dat dit heeft geleid tot een toegenomen besef dat geestelijk verzorgers niet uitsluitend 'de pastoor' of 'de dominee' zijn, maar ook inzetbaar zijn voor mensen zonder geëxpliciteerde levensbeschouwelijke oriëntatie.

Die brede inzetbaarheid van geestelijk verzorgers heeft in de afgelopen jaren ook beleidsmatig meer aandacht en erkenning gekregen. Geestelijk verzorgers zijn nu ook beschikbaar

- voor werknemers bij de politie;

- in thuissituaties, vooral in gevallen van palliatieve zorg.

Wat betreft de laatste categorie is het goed denkbaar dat er in die situaties meer cliënten zullen zijn zonder specifieke levensbeschouwelijke oriëntatie, omdat kerkleden hulp kunnen vragen aan hun eigen pastor.

\section{Conclusie}

We kunnen concluderen dat IGV niet alleen een noodzaak is in ons land met zijn secularisatie en veelkleurig religieuze landschap, maar ook min of meer vanzelfsprekend onder de beroepsgroep, en geaccepteerd door cliënten. MRB onder geestelijk verzorgers verhoogt de acceptatie van IGV nog verder. Verder blijkt de brede inzetbaarheid van geestelijk verzorgers ook in de samenleving beter zichtbaar te worden.

\section{Discussie}

Is er, in het licht van bovenstaande conclusies, nog reden de beschikbare formatie aan geestelijk verzorgers in instellingen te 'verkavelen' langs historisch 
gegroeide lijnen van kerkelijke zendingen en andersoortige accreditaties? Mijn antwoord hierop neigt naar 'nee, maar.... Het lijkt mij een goede zaak dat het 'soort' geestelijk verzorgers dat wordt aangesteld, meer in lijn ligt met de gangbare, hedendaagse verscheidenheid in levensbeschouwelijke oriëntaties onder de cliënten van een instelling, dan met 'verworven rechten' van denominaties/accreditaties. Aan de andere kant zou voorop moeten staan dat de geestelijk verzorger optimaal kan functioneren in contacten met cliënten, van welke levensbeschouwelijke oriëntatie dan ook. Daartoe is het nodig dat deze over een goede eigen levensbeschouwelijke 'humuslaag' beschikt die in hem/haar via een continu eigen ontwikkelingsproces is ontwikkeld - vanuit welke traditie(s) dan ook verworven - waarmee hij/zij in staat is 'kloppend' en creatief te spreken (Jorna 2008, 264, 291). Hij/zij zou in elk geval positief moeten staan ten opzichte van IGV. Dat zou betekenen dat het belang van de denominatie/accreditatie slechts relatief is. Het lijkt mij wel een verrijking, dat wanneer er ruimte is voor meerdere geestelijk verzorgers, dat deze een verschillende levensbeschouwelijke achtergrond hebben.

Als het gaat over de noodzaak om de professie te onderscheiden van andere, bijvoorbeeld die van de psychologie, wil ik het volgende opmerken. We weten dat psychologen ook al heel lang bezig zijn met zingeving. Verder hebben we gezien dat het in individuele contacten lang niet altijd over religie, spiritualiteit of zingeving gaat, maar dat 'relaties' het meest voorkomende gespreksthema is. Psychologen kunnen daar prima mee uit de voeten. Geestelijk verzorgers onderscheiden zich wel door hun gevoeligheid voor en kennis van de religies als 'schatkamers van levenswijsheid', en door hun rituele/symbolische en normatieve/ethische competenties. Het lijkt mij echter dat samenwerking met andere professies vruchtbaarder is dan het verdedigen van het eigen territorium.

Tot slot: uiteraard kan IGV alleen floreren als geestelijke verzorging in algemene zin floreert. Ook al versterken recente ontwikkelingen de erkenning en zichtbaarheid van de brede inzetbaarheid van geestelijk verzorgers, toch vermoed ik dat dit nog steeds een punt van aandacht blijft.

\section{Noten}

1. Dit artikel sluit aan bij mijn presentatie op het symposium ter gelegenheid van de promotie van Anke Liefbroer op 9 september 2020. Het is tevens een aanvulling op en actualisering van een eerder door ons samen in Religie \& Samenleving gepubliceerd artikel onder de titel 'Religieuze en levensbeschouwelijke diversiteit in het leven en werk van geestelijk verzorgers’ (Berghuijs \& Liefbroer 2017a). 
2. De RING-GV is een Nederlandse organisatie die diegenen autoriseert die niet door een religieuze organisatie gezonden willen worden of geautoriseerd willen worden door een humanistische organisatie. Deze geestelijk verzorgers hebben uiteenlopende levensbeschouwelijke achtergronden. Zij zijn verenigd in de SING = Sector Institutioneel Niet-Gezondenen van de VGVZ.

\section{Literatuur}

Berghuijs, J. (2018),

Meervoudig religieus: Spirituele openheid en creativiteit onder Nederlanders, Amsterdam: AUP.

Berghuijs, J. \& A.I. Liefbroer (2017),

Religieuze en levensbeschouwelijke diversiteit in het leven en werk van geestelijk verzorgers, Onderzoeksrapport, Vrije Universiteit Amsterdam.

Berghuijs, J. \& A.I. Liefbroer (2017a),

Meervoudige religiositeit in het leven van geestelijk verzorgers, in: Tijdschrift Geestelijke Verzorging, 20 (3), 13-22.

Berghuijs, J. \& A.I. Liefbroer (2017b),

Religieuze en levensbeschouwelijke diversiteit in het leven en werk van geestelijk verzorgers, in: Religie \& Samenleving, 12 (2), 121-142.

Bernts, T. \& J. Berghuijs (2016),

God in Nederland 1966-2015, Utrecht: Ten Have.

Campbell, C. (2007),

The easternization of the West: A thematic account of cultural change in the modern era,

Boulder: Paradigm Publishers.

Hart, J. de \& P. van Houwelingen (2018),

Christenen in Nederland, Den Haag: Sociaal en Cultureel Planbureau.

Jorna, T. (2008),

Echte woorden: Authenticiteit in de Geestelijke begeleiding, Amsterdam: Uitgeverij SWP.

Liefbroer, A.I. (2020),

Interfaith spiritual care, PhD thesis, Vrije Universiteit Amsterdam.

Liefbroer, A.I. \& J. Berghuijs (2017).

Religieuze en levensbeschouwelijke diversiteit in het werk van geestelijk verzorgers, in: Tijdschrift Geestelijke Verzorging, 20 (3), 24-33.

Liefbroer, A.I. \& J. Berghuijs (2019),

Spiritual care for everyone? Personal and organizational differences in interfaith spiritual care among chaplains in the Netherlands, in: Journal of Health Care Chaplaincy, 25 (3), 110-129. 